RESEARCH ARTICLE

\title{
Seeing Like a Citizen: How Being a Participant in a Citizens Assembly Changed Everything I thought I Knew about Deliberative Mini-Publics
}

\author{
John Boswell
}

This paper presents a participant-observation account of my experience as a randomly selected participant at a Citizens' Assembly. I reflect on what the unique experience of 'seeing like a citizen' can add to accepted understandings and practices of mini-public deliberation. I find that the experience, though energising, exciting and ultimately hugely worthwhile, also upended many of my prior assumptions grounded in academic scholarship and previous experience as an observer, facilitator and organiser of such events. I draw on the experience to shed new light on the capacity of assembled citizens to: accurately reflect the concerns of the broader community; soberly digest and reflect on evidence; earnestly engage in reasoned argumentation with one another; carefully reach sophisticated or thought-through recommendations as a collective; or ultimately gain a broader sense of efficacy from their engagement as individuals. The point in making these observations is neither to critique the Citizens' Assembly I was part of (which was in fact exemplary of best practice), nor to critique moves toward deliberative innovation more broadly (which I largely support). Instead, my hope is to push forward scholarship and practice to respond and adapt to little considered challenges.

Keywords: Citizens' Assembly; mini-public; deliberative democracy; participant observation; air quality; local government

\begin{abstract}
Introduction
A great deal has been written about the experiences and perceptions of citizens who participate in novel processes of mini-public deliberation. Empirical studies tend to report survey data, engage in follow-up interviews with participants and stakeholders, entail detailed analysis of transcripts, or report on ethnographic insights as a facilitator or observer (Curato et al. 2017). Regardless of method, most studies support a series of positive claims made for the practice of deliberative innovation - that it reflects the broader community, that it enables deep grappling with complex information, that it features rigorous argumentation among participants, that it produces sophisticated outcomes and recommendations, and that it increases participants' sense of efficacy in politics. None of these studies, however, has ever come from the perspective of a deliberating citizen.

The reason for the absence of this perspective is obvious - the sorts of people interested in conducting scholarship on deliberative innovation have never actually 'seen like a citizen', because they have never been a randomly selected participant. They are often organisers or instigators of deliberative innovation processes or events.
\end{abstract}

University of Southampton, UK

J.C.Boswell@soton.ac.uk
They are frequently interested observers or dispassionate evaluators. But the chances of being randomly selected to participate are vanishingly small. In the UK, for instance, recent analysis suggests that approximately 1000 people have taken part in Citizens' Assemblies to-date (Tyers et al. 2020). There are over 45,000,000 eligible voters in the country. That makes the odds of selection at just over $0.002 \%$. There is, quite literally, more chance of having won the lottery than having participated in a Citizens' Assembly.

In November of 2019, I hit the jackpot. Having dedicated much of the last 10 years to writing about deliberative democracy, I was one of just over 40 randomly selected to participate in the Kingston-uponThames Citizens' Assembly on Air Quality - an event run by my local borough council. This happenstance gave me the unique opportunity to be a deliberating citizen. This article represents an effort to reflect on what I learned from taking on this role, and to link these reflections back to more general ideas and claims about mini-public deliberation in theory and practice.

The analysis gives pause for thought on many of the assumptions that academics (like me) and practitioners have made about mini-public deliberation. Specifically, I saw in a new light presumptions about the capacity of assembled citizens to: 
1) accurately reflect the concerns of the broader community;

2) soberly digest and reflect on evidence;

3) earnestly engage in reasoned argumentation with one another;

4) carefully reach sophisticated or thought-through recommendations as a collective; or

5) ultimately gain a broader sense of efficacy from their engagement as individuals.

I want to be very clear from the outset what I am doing (and not doing) in interrogating and re-evaluating these well-worn maxims of deliberative innovation.

Firstly, my intention is not to offer a critique of the particular Citizens' Assembly I was involved in, nor suggest it was in any way a poorly run or 'improper' process. In fact, as I will explain, the Kingston CA was exemplary of best practice in the field. It was slick, professional and smoothly run, steered by experienced professionals leading the field in the burgeoning democratic sector. It has also featured an exceptional commitment to followthrough after the event, with Kingston-upon-Thames council officials taking very seriously their responsibilities to engage with the outcomes of the CA and to continue communicating their decision-making processes with the citizens involved. This commitment is indicative of an earnest and genuine commitment to best practice minipublic deliberation from the key actors involved.

Secondly, my intention is also not to critique the general worth of mini-publics like the Kingston CA. The broader move to expand the use of innovations modelled on deliberative democracy is one I largely support. While mini-publics are far from a panacea for all the ills of contemporary democracy (see Hendriks et al. 2020), this event was undeniably well timed and appropriately conceived. It was energising and symbolically important, providing welcome impetus for the borough council to tackle a thorny and largely ignored public health problem, and to begin the process of fundamentally rethinking the way it engages with citizens.

My ambition instead is to think closely about the broader deliberative and democratic values of mini-publics, and to use these reflections to help better steer the practice of innovation towards enabling and sustaining these values. The upshot might be an understanding which better recognises, supports and sustains the role of deliberative mini-publics, and their potential contribution to policymaking and political engagement.

\section{What I thought I knew about mini-publics ...}

There is something of a cottage industry of narrative reviews outlining the spread of mini-publics in contemporary policy and governance (eg. just in recent times Elstub and Escobar 2019; Dryzek et al. 2019; Curato et al. 2017). The general gist is that, while the experience of deliberative innovation is changing at a fast pace and varying in its adaptation in different ways across issues, sectors and countries, there is a growing body of evidence about the value of best-practice mini-public deliberation. Among the dozen key 'findings' in Curato et al.'s recent summary of public deliberation more broadly, five stand out as relevant for the experience of mini-public deliberation in CAs.

\section{Mini-publics and the community}

The first apparent finding is that mini-publics can enable an accurate cross-section of the population to participate on an equal footing. The obvious concern long voiced by critics of deliberative innovations more generally is that the format will skew towards the mores and norms of traditionally more empowered citizens - reinforcing the image of the wealthy, educated, older men in Athenian democracy or Habermas's Parisian salons (see Sanders 1997). The concern is that citizens with these demographic features are more likely to have the time, inclination, interest and confidence to participate. In response to this worry - and inspired in part by democratic theorists grappling with this concern-designers of mini-publics have made two key moves that grapple seriously with the nuanced dynamics of power.

One is to invest a huge amount of effort and energy in sophisticated sampling and recruitment methods to ensure a diverse demographic with a representative spread of public opinion (see eg. Fishkin 2009). Of course, there is good evidence that mini-publics are not always successful in recruiting a representative sample in practice. Real-world constraints like time pressures, unfortunate contingencies and finite resources can lead to samples that bias towards certain sectors of the community that are always more engaged politically (ie. 'pale' and 'stale' in a country like Britain). However, there is growing conviction that, if done right, Citizens' Assemblies should entail a representative cross-section (see discussion in Prosser et al. 2018).

Two is to ensure measures are in place which enable participants to speak on an equal footing. The available evidence shows that setting ground rules for conversation, and having experienced and well trained facilitators to enforce them, empowers all participants to feel included and able to contribute to deliberation (see Carson 2017a).

\section{Mini-publics and complex information}

The second finding is that citizens have the ability to process relevant evidence around complex policy issues. In public debate (and, in my experience, the private corridors of academia), there is considerable scepticism about the cognitive capacity of everyday citizens (see eg. Hibbing and Theiss-Morse 2002; Achen and Bartels 2017). On this point, however, the evidence from deliberative innovation would seem to be unequivocal - citizens can and do rise to the challenge.

In practice, different approaches to informing participants in various forms of mini-public deliberation have developed and ossified, as a consequence of shared knowledge, standards and training in the democratic sector (see Escobar 2015). Most innovations entail some form of 'injection' of expert knowledge, via information packets, guest speakers and online resource packs. Based on principles of adult education, most also enable some form of interactive engagement in the learning 
process, through Question and Answer sessions, expert 'speed-dating', or field site visits. Evidence and practical experience suggests that this prolonged learning process near the outset of the event - where participants are exposed to a shared pool of evidence - is essential to subsequent deliberation (or maybe even more important, see Goodin 2008).

\section{Mini-publics and debate}

The third finding is that citizens can grapple with this complex information as they engage in reasoned debate with each other. To be sure, the resultant 'deliberation' does not necessarily look like the rational exchange of pure reason found in Habermas's ideal speech situation. Indeed, deliberative theorists as well as practitioners interested in deliberative innovation have long turned their back on pure reason as an alienating and exclusionary norm. Instead, they welcome greeting, storytelling, colour, humour, and all the other ingredients of everyday social interaction (Dryzek 2000); this multiplicity of communicative mode is increasingly built into the practice of mini-public deliberation, with participants encouraged to express their views in ways that are personally comfortable and culturally secure. The evidence seems to show that, in this more expansive view of what reasoned debate might entail, citizens can and do rise to the challenge. Mini-public deliberation consistently scores highly (and higher than established democratic institutions) on measures of reciprocity and mutual respect (Pedrini 2014).

\section{Mini-publics and consensus}

The fourth apparent finding is that mini-public deliberation can lead to collective recommendations that capture and convey the (refined) beliefs of participants. Though often associated with the pursuit of consensus (in popular imagination and certain strains of academic criticism), most deliberative democrats are willing to accept that there may be irreconcilable views among citizens on complex and contested issues. Consensus, in theory and in practice, is a bar considered much too high for the 'real world' of democracy, and with worrying coercive implications if pursued too vigorously.

So mini-public deliberation typically aims at metaconsensus, an enlarged understanding of the terms of debate and the implications of different perspectives in practical terms (Niemeyer and Dryzek 2007). In practice, this means the work of Assemblies is geared at producing a set of recommendations rather than a consensus outcome. The production of recommendations is typically the end goal facilitators urge participants to strive for. The codification of these recommendations is often the chief output that organizers then feed through to commissioners of mini-publics. Most such documents leave room for contextual explanation - about the depth or breadth of feeling, and the existence of competing interpretations or views among the group. These practices exist under the assumption they enable broad buy-in from participants to the process, and support for the outcomes of deliberation as a whole. The available evidence suggests mini-public deliberation is successful in achieving these more modest goals (Curato et al. 2017).

\section{Mini-publics and political engagement}

A final key finding is that engaging in mini-public deliberation has a transformative effect on participants and participation (see also Knobloch and Gastil 2015). Though typically pursued with more instrumental or direct aims (ie. providing insight into refined public opinion on a difficult political problem), a beneficial side-effect is that mini-publics act as a kind of 'school of democracy'. The experience of engagement is seen to have an impact on participants' sense of political agency - whether from the social benefits of engaging in civic life, or the knowledge benefits from understanding politics and policymaking better, or some combination. Evidence shows that participation in a mini-public enhances people's trust in democratic politics, and boosts their belief in their own political efficacy.

Recent developments in practice seeking to 'follow through' more thoroughly after mini-public deliberation are in part designed to tap into this feelgood factor (Gronlund et al. 2010; Christensen et al. 2017). The hope is that continuing dialogue with participants, and using them to spread the message in their communities, can ensure a legacy impact from mini-public deliberation for a more active and inclusive civil society.

\section{Methodology: Seeing like a citizen through participant-observation}

The paper originates from the unique experience of being a participant-observer of a Citizens' Assembly. In this brief section, I explain how the opportunity arose to conduct this form of research, the benefits of participantobservation as a method, and how I went about being a participant-observer in this case.

Over two weekends in November 2019, the KingstonUpon-Thames Borough Council held a Citizens' Assembly on Air Quality at the local university campus. The process was run by consultants from the Involve Foundation, the leading democratic engagement specialist in the UK, and featured many of the standard characteristics of bestpractice mini-public deliberation (random selection of citizens, experienced independent facilitators, expert presenters, and a lively range of formats and tasks).

I received an invitation to register in the post in September. I registered my details on the online system, and received an email confirming my selection in October. During a follow-up call with an Involve representative, I revealed my professional background. We confirmed this would not disqualify me from participation in the process - and that I would be free to note observations and impressions so long as nothing I did had a material impact on other people, and that I would not be unduly distracted from my primary role as deliberating citizen. I was free to be an embedded ethnographer at the event.

Of course, ethnographic methods have been a staple in the study of deliberative innovations (see eg. Hendriks 2012; Johnson 2015). Many academics have acted as neutral observers from the edge of the room or beyond 
as events unfold and deliberation takes shape (eg. Ryfe 2006; Dean et al. 2020). More commonly still, others have taken on the role of action researchers, actively engaging in the process as leaders, co-ordinators or facilitators and reflecting on their experiences and observations (eg. Prosser et al. 2017). In these latter cases, oftentimes the process is itself embedded in a research project designed to test claims in deliberative democracy. The findings from these ethnographic studies have been vital in identifying promising new innovations (Fung and Wright 2003), exposing pervasive inequalities or pathologies (Johnson 2015), and teasing out contextual nuances in practice (for a comprehensive review, see Ercan et al. 2017). But there are also limits to the capacity of these approaches to get inside deliberative practice. Outside observers usually cannot listen in on small-group deliberations, and are typically barred from informal or incidental engagement with participants during the process. Action researchers are conflicted with the demands of their dual role - the urgent tasks of delivering the event (running the schedule, keeping everyone on task, facilitating discussion, capturing artefacts and data) can emotionally and cognitively crowd out opportunities for being 'in the moment'. The result is that even these up-close observational studies fail to penetrate the fuller lifeworld of a deliberative process the familiarisation with each other and roles, the process of learning and discovery in expert sessions, the informal chat among participants during breaks and afterwards.

Being a randomly selected citizen gave me access to this fuller lifeworld. To be sure, the approach is not without its limitations. I was only able to observe what was around me, and not always the broader room. More obviously still, I had no control or say over the actual context and content. There was no careful case selection process. By random luck, the case chose me (see Soss 2018). I was also conflicted with my own dual task - embodying the deliberating citizen in the moment while at the same time having an out-of-body experience as a critical observer. Nevertheless, in however partial and piecemeal a way, the experience afforded unparalleled authenticity in access to the experience of seeing like a citizen.

My approach to participant-observation in this case followed a long tradition in the study of politics and policy (de Volo and Schatz 2004). I was first and foremost a participant, committed to engaging in my specified role and performing it to the best of my abilities. (I will document in due course how difficult I found this to do). But I was also an interested observer of what was happening around me. In particular, I used the 'down time' at the event to get to know my fellow citizens and the facilitators. I sought out different people to speak with. I elicited their views about the process and asked them questions about their experience. The challenge was to inquire naturally, without appearing to probe or intellectualise. In practice, I found an open-ended question like 'Have you ever done this sort of thing before?' or 'How are you finding it?' was normally enough to spark an organic conversation.

To capture data, I set about recording observations and impressions in-the-moment and afterwards. During the event, I snatched opportunities to take unobtrusive notes. I scribbled brief thoughts on pieces of paper, post-it notes and other paraphernalia left on small group tables. However, in line with what I had agreed with the organisers, I did not want to draw attention away from the serious business of deliberating. In any case, I was often too busy interacting with people or listening intently to proceedings to take notes 'in-the-moment'. In practice, then, these short-hand notes operated more as memory aides in recounting the experience than as blowby-blow accounts of the proceedings. More important for my analysis and interpretation was the detailed documentation I jotted down in my fieldwork notebook each evening. Once home after the conclusion of a session, I would transcribe whatever notes I had assembled but also record fuller reflections on what I had experienced and witnessed. The practice was like keeping a diary of the event (Boswell et al. 2019).

The analysis took the form of abduction common to interpretive research (see Yanow and Schwartz-Shea 2013; Boswell et al. 2019). My analysis, in this sense, was neither purely inductive (emerging from the field) nor purely deductive (driven by the literature). It involved moving between the two. I began with knowledge of theory founded on a decade of research, but drew on my experiences to interrogate theoretical claims and think through how they might be refined. The aim, in this interpretive orientation to research, is not to prove or generalise claims, but to open up, explore and shed new light on established claims and ideas, and inspire further detailed study. As such, the discussion below centres around the five themes spelled out in the literature review, and follows through to explore ideas for rethinking or reimagining these claims and ideas based on the findings.

\section{Inside the Lifeworld of a Citizens' Assembly}

In practice, I found the experience as a citizen significantly different to that of being an observer or organiser/facilitator. It shifted or inverted many of my preconceptions, including those largely backed up in observational studies of mini-publics. In this detailed section, I return to the categories established earlier to reflect on how 'seeing like a citizen' might change or refine our presumptions of CAs specifically and, where appropriate, mini-public deliberation more generally.

\section{Revisiting mini-publics and the community: Is anyone sitting here?}

The most striking thing on the first day was the overwhelming sense of awkwardness. This was especially acute during 'down time' in breaks between sessions. We were ferried into an adjacent room - a university bar/café - with a lunch buffet and some people serving cups of tea. But what were the rules of engagement? The initial queue for the buffet was a long awkward silence. Most people shuffled along, looking at their shoes, fussing over their cutlery, or umming and ahhing over their choice of sandwich and fruit. Now we had to sit down, among about 25 tables of various sizes. Was it like a bus, with the obligation to fill up the tables as singles first? Or should we try to be sociable? Should we sit with people from our mini-group discussions, or just with anyone? Gradually, tables with one person became tables for two or three: 'Is anyone sitting here?' the universal 
refrain of tentative friendliness. My table near the buffet quickly swelled to five, all co-deliberators from my small group back in the main hall. Relieved to have the social uncertainty resolved, we began some friendly introductory chatter. Most of the tables around me exhibited the same dynamic, as people settled into this new social norm. Or did they? I was struck by the stark demography - I seemed to be the youngest of the chitchat brigade by about ten years. At the back of the room, in ones and silent twos, were the younger members of the group, and many of the visible ethnic minorities as well. They were staring at their phones, their body language largely turned off to any prospect of company.

The vignette points to the depth of the challenge when it comes to inclusion in a deliberative process. The experience of 'being there' and a part of proceedings, especially in the 'down time' where organisers and observers are usually not involved, highlighted a distinction between formal and informal inclusion.

Without doubt, the organisers had put tremendous effort and resources into formal inclusion in the process. In line with best practice, they employed stratified random sampling to ensure the people in the room were representative of the wider borough. They even went above and beyond the norm, making a special effort to incorporate a balance of gender and ethnicity among expert speakers and presenters. And proceedings included carefully designed familiarisation and breakout activities - eg. an improv game involving a paperclip-to lighten the mood and encourage a welcome and relaxed atmosphere.

But for the informalities, like the experience in the break room, we were left to our own devices. It is here that genuine rapport and mutual understanding flourished but only among an exclusive demographic. Throughout proceedings, I made a point of seeking out some of the people at the back of the room who were not joining in the informal chatter. Despite my best efforts, not all were particularly forthcoming. However, two of these 'wallflowers' in particular gave me insight into what this informal (self-)exclusion meant in practice. One was a young IT consultant who hated normal politics and wanted to engage in something deeper. Another was a recent immigrant who had come out of concern for his young son's respiratory issues. For the former, it was clear that informal exclusion was no barrier to his engagement in table deliberations. He was happy to have his say. Indeed, as a recent university graduate and office worker used to seminars and meetings, I could see that he thrived in the environment without any need for building rapport or social familiarity. For the latter, however, exclusion in the breakroom reflected a lack of engagement in deliberations. On the days we shared a small group table, he said almost nothing at all, even after multiple subtle (and not-sosubtle) prompts from our facilitator. His only interjection was to ask an expert for personal medical advice, revealing he did not actually understand the purpose of the exercise and further alienating him from everyone else around the table. His story was extreme but not isolated - indeed, it was mirrored to a lesser extent by others I interacted with who had English as a second language (also, of note, a huge proportion of the local citizenry).
The observation about subtle, informal exclusion is not meant as criticism of the event. Certainly, some (better resourced) processes invest more in building an espritde-corps through, for example, formal dinners. But there are obvious trade-offs. It was striking in chatting to people informally how deeply inconvenient the event was for them, how many people had to reshuffle their shiftwork or arrange ad hoc childcare just to take part - reasons that notably chime with Jacquet's (2017) account of why people choose NOT to take part in mini-public deliberation. It was also striking how emotionally draining most of us found the process. So it cannot just be a case of scheduling a predeliberation meal and hoping that sorts the problem out. Some people will not have time to partake more in social events. More still will run out of inclination.

Instead, the observation speaks more to the need to target efforts to build capacity among participants representing vulnerable or marginalized demographics. Doing so can make claims to formal representativeness more robust to the hidden or informal world of social interaction - a point I return to in the conclusion.

\section{Revisiting mini-publics and complex information: Question the facts!}

There are only so many expert presentations you can hear on air quality before they all start to blend in. In fact, after two days of it, the only thing I really remember in any detail was the stark contrast of the day's final speaker. He started - sans any apparent credentials - by telling us to 'question the facts', assuring us that he would provide full evidence for all of his claims. (This implied other speakers had not, when in reality they had abused us with footnotes and detail). He proceeded to provide no evidence for anything he said whatsoever. His talk was seemingly random, spanning industrial use of hydrogen cells, the evils of wind turbines, and personal car battery maintenance, via awful clichés and baffling quotes. His presentation was so devoid of evidence/logic that I felt compelled to Google his affiliation while he spoke. It turned out his company, Saipem, is an international energy company with its headquarters in Kingston. If he was trying to communicate a logical point, it was completely lost on me-but he did keep telling us to 'question the facts'. I had pegged him as some sort of lowrent Merchant of Doubt. ${ }^{1}$ I turned to my neighbour, a closet Extinction Rebel and keen reader of environmental science, and we mutually exchanged eye-rolls as I showed her on my phone our 'expert' speaker's background. Assuming our cynicism was in the majority, I turned to the table once he finished: 'What the fuck was that all about?' I had not read the mood. ${ }^{2}$ My outburst visibly shocked the other people at the table, who had apparently found the speaker 'great' and 'a breath of fresh air'. 'I thought some of his points were very interesting.' 'Yes, I liked the way he kept telling us to "question the facts".'

To be clear, I do not tell this story to show off about my own 'superior' skills for distilling and critically examining complex information. I too zoned in and out of the expert testimony. Like everyone around me, my attention waxed and waned significantly during that first weekend: I got hungry that second morning having had to skip breakfast to make it on time; I needed a coffee after lunch because 
I had forgotten to top up before we were called back in from the breakout room; I felt overwhelmed and bored by much of the technical detail. I only noticed the particular episode in this vignette because I was in an unusually heightened state of attention.

The vignette, then, speaks to a broader point about how people actually process information in a context of sudden 'overload' on a complex issue - an experience about which ethnographic studies have provided valuable insight already (see eg. Settle 2016) but which, understandably, has seldom been a major focus of investigation. The interesting or exotic part of a process like a Citizens' Assembly is the citizen deliberation. But for a deliberating citizen, just like much of the social energy is actually spent during the 'down time' in breaks, much of the cognitive energy is channelled as passive listening. (Ironically, in my experience, expert testimony usually coincides with 'down time' for observers, organisers and facilitators who 'switch off' waiting for the next phase of the event). What actually happens during this time is then of vital importance to our overall understanding of mini-public deliberation. In this sense, the point of the story above is that (almost all) participants are not learning in the cumulative way an event is organized - over the course of a long process, the overload of new information is overwhelming, and any individual is likely only to take and hold on to fragments or snippets of information. My experience supports the claim that learning is far more important symbolically than it is instrumentally (Forester 1999).

There is a significant scholarly and grey literature devoted to 'best practice' on informing citizens about complex issues in deliberative processes like Citizens' Assemblies. Much of this work recognises the problems associated with the 'empty vessel' approach to filling citizens up with new knowledge, and promotes a variety of styles and approaches to learning (see especially Carson 2017b). Some of the techniques associated with this more nuanced or dynamic approach to learning were in play in the Kingston CA. Experts were not all of a kind - there were scientists and academics, local government practitioners and civil society actors, and consultants and industry representatives (like the one in the vignette). Moreover, expertise was not always delivered from on-high in 'broadcast' mode. After speaking, experts circulated small tables, where we could grill them on the details of their presentations or ask them to elaborate on tangential issues. One or two came back later in the process to address lingering questions and concerns. Information was also made available on a weblink for participants to refer to on the break between weekends.

The variety helped. The active engagement helped. But even so, I found myself 'coming and going' out of presentations and technical discussion sessions, with increasing frequency as time passed. The participants around me seemed much the same. One neighbour confided that she was struggling to concentrate because her young child had kept her awake in the middle of the night. Another admitted he was impaired a bit at times because he was feeling the ill-effects of a big night out. I lost count of the number of times I caught people nodding off through the afternoons on the first weekend. We joked at my table on the second day about bizarre snippets we remembered but could not make sense of their context: why was that professor talking about bacon? what did that pretty graph mean again? who was the person banging on about parking schemes? This is not to say we learned nothing - we clearly did. But the actual learning of the information that was intentionally conveyed was haphazard, piecemeal, idiosyncratic, depending on our own fluctuations in fortune through the process.

Much more important than the specific details of what we learned was the collective sense of grappling with something together. This was the (unintended) appeal of the offending speaker's call to 'question the facts'. It was noticeable as the process evolved that people became more confident about asserting their own knowledge. Around my table, people would explain: 'But that contradicts what another speaker said'; 'I have been reading up about this on the internet between weekends'. It did not really matter whether these sorts of assertions were accurate, even if they could have been verified. What they spoke to was a symbolic shift in status. As knowledge washed over us, we were becoming the experts.

If that shift is the important end goal of 'learning' in a deliberative process, then there are almost certainly much more effective and efficient ways of getting there than through two days solid of expert testimony - a point I return to in the conclusion.

\section{Revisiting mini-publics and debate: It was such a relief to hear from the expert yesterday}

We kicked off the third morning with a reflection on what we had learned' and how we might use that learning to guide our thinking about policy recommendations. We went around the table in a circle. People variously spoke earnestly about some fact about air quality that stuck in their head, or they made a light-hearted joke about it being too early to engage their brain. Until we got to Jim. I had chatted to Jim for the entirety of the afternoon tea break the previous Sunday - a lovelier bloke you are unlikely to meet. He was someone everybody evidently warmed to. His big 'learning', he said, was that it was okay for him to keep using his old woodburner at home. "It was such a relief to hear from that expert. He said it was fine. You know, us older people, we like the security of having an old-fashioned fire in winter. It is so good to hear it doesn't contribute to air pollution'. There was a collective doubletake around the table. In fact, the expert had said the precise opposite. He told us unambiguously that most domestic woodburning was an egregious and entirely avoidable contributor to local air pollution. Jim had, somehow, completely misconstrued. But to point out his mistake would be to humiliate him - to impose social guilt on him for a practice he clearly cherished, and perhaps worse to impugn his cognitive faculties in front of everyone. So, we all politely nodded along, leaving the claim unchallenged so we could quickly end this discussion and move on to the next person.

This vignette highlights an under-appreciated challenge in deliberative mini-publics - disagreement. Ordinary social interaction is not like the philosophy seminar on 
which the deliberative exchange of reasons is modelled. In face-to-face interaction in ordinary life, expressing disagreement comes with a high social cost. To challenge a claim is to run the risk of offending the person you disagree with, and of appearing rude or inconsiderate to everyone else.

So much of the emphasis on the value of mini-publics in general - and the Citizens' Assembly model especially - stresses their constructive or consensual dynamics. After all, they are held up as ideal 'recipes' in contrast to the increasingly polarized and toxic public sphere of the real world. This has been a huge part of the 'sell' in the recent proliferation of Citizens' Assemblies in the UK (Prosser et al 2018). What this underestimates is the difficulty in expressing disagreement in the real world of social interaction, perhaps especially in a discursive culture like Britain which puts a premium on being polite and indirect. Some existing studies tease out the dynamics of disagreement and dissension in interesting ways. David Ryfe's (2006) observation of small group deliberations, for example, reveals how people use stories to challenge claims indirectly. Likewise, Laura Black (2009) reveals how humour and personal anecdotes help people from opposite sides of a debate overcome impasses. Hartz-Karp et al. (2010) show how participants 'other' powerful actors not directly involved in discussions to create collective buy-in across diversity.

But in my observations - as with the story of Jim above - most people found it difficult even to attempt subtle expressions of disagreement. There were a couple of notable exceptions. Ella, a highly qualified professional, was more than happy to take people to task. Frank, a businessman who clearly enjoyed the sound of his own voice, seemed to positively enjoy playing Devil's Advocate. But they were the stark exceptions rather than the rule. Instead, most of us were more suited to deference and diffidence, happy to let things go rather than make a scene. The overwhelming impression was of the minipublic as a social experience, rather than as a high-stakes political setting. For most of us, in these circumstances, it was much more important to be nice than to be right.

The experience reinforces long-voiced concerns that the pursuit of consensus in mini-public deliberation might have a chilling effect, or reflect small group social pressures rather than any 'forceless force of the better argument' (see Karpowitz and Mansbridge 2005). It also reinforces a need in practice for priming disagreement and contestation - a point I revisit in the conclusion.

\section{Revisiting mini-publics and consensus: I don't know. What do you think?}

Today (the final day) was a 'hard' day for everyone. People began to look visibly tired and overwhelmed as the day went on. We were tasked with coming up with a list of recommendations. Inevitably this meant synthesising a lot of ideas and trying to frame them in the most compatible and compelling way possible. As someone who does this all the time - as a researcher searching for patterns in qualitative data, and as a teacher reaching for heuristics to communicate complex ideas - it never really occurred to me how difficult and unintuitive this exercise actually is for people. We had to turn dozens of little post-it-note suggestions on each area into a comprehensive and snappy list of 4 or 5 priorities. After the relative freedom of the 'ideation' phase yesterday, liberated from the constraints of the expert testimony and left to come up with our own suggestions, it was noticeable how most people at my table retreated at this point. We were not sure how to amalgamate the multiple interrelated suggestions relating to each point, or what level of abstraction to pitch the amalgamated ideas at. We did not want to offend anyone or leave any of their ideas 'off the table'. Increasingly, when singled out by the facilitators, my fellow deliberators would seek to pass the buck: 'I don't know. What do you think?' A group that had started the day bubbly and forthcoming was suddenly uncertain, tongue-tied and frustrated.

This vignette highlights another under-appreciated challenge or presumption built into any mini-public engagement method that is consciously open-ended. There is, of course, a powerful logic to the value of the open-endedness often characteristic of Citizens' Assemblies especially. It rests control over the agenda in the hands of the deliberating citizens, rather than organisers or commissioners (see Smith 2009, ch2). The trouble is that, in practice, it is awfully demanding on the citizens involved.

Having dutifully pushed myself to 'step back' (in the vernacular of our 'meeting rules'), I found this final task of the Citizens' Assembly especially frustrating and painful. For this final day, each table was assigned a particular topic or area (ours being education and communication). The facilitator asked us to look at an unruly set of post-it note points and group them into neat recommendations. The result was a tentative, confusing mess. We ended up with recommendations that ranged from the bizarrely specific to, more often, 'motherhood and apple pie' platitudes. Some points were just clumsily adjoined lists. Most were worded in ways that were long-winded and unclear. (We later moved around the room and saw what other groups had produced in relation to their key issues such as public transport, planning and construction, etc. They had fared little better). What was noticeable was the stress and strain this process induced around the table, and the palpable relief when we had 'finished'. Some people completely checked out. Others were looking furtively around the room when the facilitator asked for opinions. Most of us kept deferring or answering the question with a question. It recalled for me some of my own stresses in previously acting as a mini-public facilitator in trying to balance the 'task' orientation of producing outcomes from deliberation with the 'process' orientation of ensuring inclusive and fulsome discussion.

The result, of course, was that almost nothing we suggested was clear, specific, and implementable. In practice - I should stress - leaders and officials in the borough council have taken these recommendations very seriously. In the year following the event, they methodically took them into consideration in the development of their official air quality strategy. They have even engaged participating citizens from the Assembly in a series 
of follow-up events to discuss the evolution of their thinking, and elicit feedback to ensure the spirit of the recommendations emanating from the CA has not been lost. Theirs has been an earnest and genuine commitment to following through in accordance with best practice. But the experience speaks to the potential for cynical exploitation in a context that is less politically benign. Indeed, it is not hard to see, in other contexts, how the lack of immediately usable inputs for policy might constitute a 'dream' outcome for cynical decision-makers who want the feelgood factor from the event along with the chance to selectively cherry pick and fudge their official response (as in Johnson 2015).

Of course, the balance between maintaining an open agenda and ensuring a realistic chance of policy uptake is not new or undiscovered in this field. In fact, it represents a perennial challenge in deliberative innovation in myriad forms - especially CAs which tend to have an open-ended remit or license to generate bottom-up recommendations. However, what it does reveal is a more nuanced understanding of how this challenge comes about. The blame for this state of affairs is typically laid at the feet of unresponsive elites. The presumption is that they cannot countenance the radical challenge or 'out of the box' thinking of citizen deliberation (see Lee 2014). But this inside observation reveals that mini-public deliberation is often not optimally set up to produce usable outputs - and that usefulness is extremely dependent on the good faith of empowered elites (as in the Kingston CA case). Certainly, with the problem properly acknowledged, there may be better ways to manage the challenge in designing mini-public deliberation too - and again I come back to this in the conclusion.

\section{Revisiting mini-publics and political engagement: I just feel so deflated}

At the very last afternoon tea of the $C A$, the main discussion point was the lack of cakes and biscuits on offer. For an event that had wildly over-catered on all the previous days, we agreed in the queue for the buffet (tongue slightly in cheek), it was an immense let down not to have a sugar rush for the final stretch. After returning to the main hall and sitting down with my small group just before we kicked off again, I shared my mock outrage with Sarah across the table. She replied deadpan: 'It's a bit of a metaphor for the whole thing, isn't it?' 'Huh? How so?' She elaborated that she had found the process of arriving at and endorsing recommendations rushed and unsatisfying: 'I just feel so deflated'. Gary, sitting next to her, chimed in: 'I agree. The council will just ignore [our recommendations].' 'Maybe that's what they wanted all along.' Gary, so enthusiastic when I first spoke to him last weekend, was becoming disillusioned: 'See, now it's made me feel cynical about the whole thing. I didn't want to be cynical. But I am now.' By this point in the conversation, Sarah was scrolling through her phone reading out comments from a local Facebook page where people were mocking the concept of the CA and criticising the council for wasting money on such frivolities. 'I don't blame them!'
This vignette highlights a perennial challenge often glossed over in the rush to celebrate the impact of minipublic engagement on political efficacy. As explained above, studies of mini-public deliberation generally find an incidental or 'intrinsic value' to engaging citizens. But 'being there' among participants gave me quite a different perspective. Sarah and Gary were not the norm, but they were not complete outliers either. There was a range of perspectives on the process. Some people seemed to remain upbeat till the end, but there was also a sizeable population of discontent that developed too. In fact, at both my tables towards the end of the $3^{\text {rd }}$ and $4^{\text {th }}$ days, I witnessed participants become sceptical about what was happening and instigate minor 'process rebellion'. There was a collective worry that we might be wasting our time. ${ }^{3}$

In the scholarly and grey literatures, claims around political efficacy tend to be based on survey response data captured in the immediate aftermath of a mini-public (as in Prosser et al. 2017). Methodologically, the reason for gathering data then is clear - the researchers still have a captive audience and can ensure a high response rate. But this moment coincides with a consummation in proceedings: when people are happy to have finished something arduous and challenging; when they are saying pleasant farewells to friendly people; when they have just been given warm and fuzzy feedback from the organizers and commissioners in positions of authority. Similar data captured in the Kingston CA no doubt produced rosy formal evaluations. Gary even said to me that he didn't want to 'cause trouble' or 'put anyone out of a job' as we filled out our evaluation forms. That did not mean that he actually thought the process was instrumentally useful, or that he actually came out of the event feeling newly empowered. It just meant he was being nice.

This observation speaks to the prospect of refining claims about the incidental or 'intrinsic value' of engaging citizens in mini-public deliberation. It suggests the value might not lie so much in instilling a sense of political efficacy, but of marrying a (largely) positive social experience with a valuable insight into the complexities and challenges of policy and politics. Certainly, relative to the naïve enthusiasm Gary exhibited on the first evening, he ended up feeling more akin to how most 'empowered' actors feel about policy and politics - that it is obtuse, complex, and endlessly frustrating (Boswell and Corbett 2015).

\section{Discussion: Reflecting back on deliberative practice}

In this section, I suggest some key proposals for Citizens' Assemblies (and perhaps similar mini-public innovations). The aim, consistent with an interpretive approach to abductive reasoning (see Boswell et al. 2019), is to take the insights from fieldwork (ie. the Kingston CA) and use them to inform theory (ie. understandings of how minipublic deliberation ought to work). These ideas spring from the surprising or counterintuitive observations I made in the field. They are intentionally provisional and provocative, designed to push forward thinking in this area, rather than assert any new orthodoxy. 


\section{Don't treat everyone equally}

I have highlighted the important and largely hidden social world of Citizens' Assemblies - in the queue for the buffet or around the break room. I was struck especially by the subtle discrepancies between formal and informal inclusion, and the implications for deliberative practice. In particular, this insight calls attention to the need not to treat everyone equally if we want them to participate equally. Some people embrace the social experience whole-heartedly, around the conference table and the coffee table. Some people do not need the comfort of social rapport to embolden them to share views in the formal deliberations. But others - especially those from marginalised groups or with language difficulties -need support before and during the event to have any hope of participating on an equal footing. We can reach into the established toolkit of deliberative innovation here for approaches that help representatives from marginalised groups build solidarity and capacity prior to the event, or that ensure there is targeted mentoring and facilitation during it. The specific technique will almost certainly depend on context. What matters is a closer attentiveness to informal, as well as just formal, inclusion.

\section{Don't take learning literally}

I have also experienced as a participant what it is like to be on the receiving end of an avalanche of information in the 'learning' phase of mini-public deliberation. But I have argued learning is still valuable. Pragmatically, a certain level of competency does wash over individuals through exposure to information and active engagement in discussion. Symbolically, the learning process empowers participants to feel they have the requisite expertise to deal with a complex issue. The point is that, seen this way, learning does not need to be taken so literally. Participants are not assembling a jigsaw puzzle of information in realtime. They are coming and going, through short periods of high attention and long periods of low attention. There is no need to cover the breadth of a remit in equal detail. It also need not be such a passive activity that risks stunting any budding social interaction and rapport among the group. More active approaches to learning - through, for example, the expert speed-dating used in the Kingston CA, or field trips or experiments in citizen science used elsewhere - may therefore be more valuable (see also Carson 2017b). This way, participants can learn while also having fun, building rapport and developing their deliberative capacity.

\section{Don't prime 'nice' discourse}

I have shown that the experience of deliberating is one in which the demands of the social situation - to be considerate and polite - can override the demands of the political issue - to express disagreement with others. Of course, deliberative democrats in theory and in practice no longer support the ideal of consensus (Curato et al. 2017). But the legacy of this theoretical starting point is a set of facilitative practices which continue to prime consensusseeking behaviours. There are also concerns with how an overly appreciative and welcoming tone can spill over into the relationship between participating citizens and the commissioning body - forming a warm 'group hug' that stunts valuable contestation and critique of existing policies and settings (Curato et al. 2013). The 'conversation guidelines' that facilitators elicit in the initial stages of mini-public deliberation invariably uphold values of respecting other viewpoints, listening, being constructive, seeking compromise. The ongoing appeal is obvious the contrast with the 'toxic' public sphere helps to mark out mini-public deliberation as special and distinct. Yet the lived experience of deliberation suggests respect and reciprocity are patterns most participants will intuitively fall into given the prevailing social cues. Put simply, being nice is the default. What is missing is stronger license to disagree with each other, especially among those less experienced and confident in argumentative discourse. In practice, it points to a need to devote more attention to equipping all participants with the skills to push back against claims they disagree with, or to have their distinct point of view heard (as in Carson 2017b).

\section{Don't hand participants control of the agenda}

I have revealed the immense difficulties of leaving citizens to create policy recommendations from the bottom up. The theoretical appeal of open-endedness in practice places an unfair burden on citizens that leads to confusing claims easily sidelined in political debate. The risk is that it sets mini-publics, especially the Citizens' Assembly model, up to fail. Deliberative innovations which are structured or layered to better filter choices in an iterative process (as in Renn et al. 1993), or which offer citizens a binary choice or at least limited set of options (as in Knobloch et al. 2014), avoid this risk. Moreover, a few prominent ethnographic studies show that a clear structure does not necessarily inhibit bottom-up intervention. The citizens in the health jury John Parkinson (2004) studied went beyond the binary option given to them (which facility to close) and reached a compromise that broke the policy impasse; the citizens in the environmental planning cell Maarten Hajer (2005) studied refused to conform to the elite framing, and turned proceedings on their head. The point is that, certainly in processes of the duration and nature of the Kingston CA, citizens are in a much better position to make collective judgments on the basis of a clear framework of choice, even if that judgment ultimately reimagines the choices involved. The more democratic option in practice may be to limit the agenda.

\section{Don't pretend mini-publics are apolitical}

The last finding spoke to the incidental or legacy impact of mini-public deliberation on citizens. My own experience pointed to a good deal more disappointment and frustration with the process than typically emerges from existing academic studies and practical evaluations. That may be down to pure chance, or contagion from my critical gaze. But there is a plausible claim that it reveals the flaws in typical evaluations, conducted as they are under a context vulnerable to social desirability bias. In fact, it is not surprising that citizens become frustrated and disappointed. They start to understand how things work 
- that it is difficult to put together meaningful ideas for policy change, that their ideas will not be magically taken up by policy elites, that there are competing priorities and powerful obstacles to implementing change. One interpretation is that fermenting disappointment and frustration, rather than a naïve sense of efficacy, is not so bad after all. But a potentially more transformative idea is that organisers and facilitators might do better to be more open about the limitations from the outset. Most practitioners in this field are acutely aware of the vulnerabilities of citizen deliberation in the policy process (see Dean et al. 2020). The point is that this political context is seldom communicated to participants. Certainly, while the advisory nature of the Kingston CA was made clear to us as participants, we were never told how that advice would work in practice, and how we could best adjust and channel our efforts to make a genuine difference. In other words, organisers and facilitators should stop pretending that mini-publics are some sort of apolitical injection into the policy process, and be more reflexive and transparent with participants about their purpose and function in the democratic system.

\section{Conclusion}

'Seeing like a citizen' reveals that many of the assumptions about mini-public deliberation in theory, and some of the techniques and approaches engrained in practice, require some reconsideration and recalibration. I want to use the conclusion to clarify what I am saying and what I am not saying. I do so because I worry this analysis and argument will be taken the wrong way - or more specifically, taken two wrong ways.

On the one hand, I fear those out of field, namely generalist readers in political science and policy practice, may see the analysis as undermining the claims of deliberative democrats. Sceptics among them may pounce on it as ammunition that deliberative innovations don't work or are a waste of time - and, in the UK especially, to push back against the proliferation of Citizens' Assemblies at local level and via Select Committees in Parliament. That is not my intention at all, and not the implication I seek to draw from the analysis. Participating as a deliberating citizen was an opportunity to witness first-hand the symbolic value of mini-public deliberation and its capacity to break open new possibilities in democratic governance. It was, without doubt, a special event with a palpable enthusiasm emanating from all the participants, organisers and stakeholders involved. It offered a novel 'circuit-breaker' both for the politics of improving air quality and for the relationship between the local authority and its citizenry. And despite the critical observations I have focused on here, it no doubt achieved some success in pushing forward air quality policy and citizen engagement in the polity. It certainly seems to have been adopted and adapted by the Borough Council in good faith, as they develop a new air quality strategy that draws at least somewhat on the insights gained via the CA process, both for policy inspiration and more pointedly for political legitimacy in pushing through potentially unpopular reform. The point of my analysis is simply to better pinpoint the ways in which this symbolic value might be reinforced and leveraged to have a more authentic impact and greater lasting legacy.

On the other hand, I fear those in the field, with a research interest and/or practical experience of minipublic deliberation, may be hostile to criticism. Given the historical appetite in this field for 'good news' (see Spada and Ryan 2017), I fear they may try to write my claims off as somehow emblematic of a 'bad' Citizens' Assembly or an idiosyncratic experience. But the Kingston CA was an example of 'best practice' run by vastly experienced professionals. If anything, it was more professionally outfitted, well-resourced and smoothly run than any I have previous experience of. Writing it off as a 'bad' outlier would be an insult to the field leaders involved. Moreover, I did not deduce my key observations - about inclusion, about learning, about deliberation, about outputs, and about efficacy - in a vacuum. They chimed with inchoate or poorly articulated experiences as an observer, facilitator or organiser of half a dozen such events across Australia and the UK over the last decade. They bore affinities to nagging doubts and reflexive discussions I have had with other scholars and practitioners in the field over that time. They helped make new sense of the acres of scholarship and practical guidance I had read on the topic. The point is that I better saw these problems-and better imagined solutions to them-because of the perspective I was offered.

So, in concluding, I hope that my experience of 'seeing like a citizen' can become an important reference point for reflection in the field - especially now that ideas about, and practices associated with, mini-public deliberation are gaining mainstream traction in places like the UK. Amid the opportunity to capitalise on this novelty and newfound popularity, the ways in which proponents organise and practice deliberative innovation now are likely to become 'sticky' and hard to change. Now, more than ever, is the time to take stock - and there is firm evidence that practitioners in the field in the UK and beyond are doing so (see eg. Involve 2019). I hope that subtly reconsidering and recalibrating how mini-public deliberation works, taking the citizens'-eye-view offered here, can be an important part of this reflection and consolidation.

\section{Notes}

${ }^{1}$ This is a reference to corporate lobbyists paid to sew confusion in public understanding and debate about science, as described in Oreskes and Conway (2010) and later popularised in a documentary of the same name.

${ }^{2}$ Readers might be amused to hear that the facilitator felt compelled to remind me of the agreed 'conversation guidelines'.

${ }^{3}$ To be crystal clear, I do not raise these observations to be critical of the way the event was run - in fact, facilitators and organisers handled these rebellions with integrity, adaptability and a great willingness to listen, even amending some of the procedures on-thehoof. They were exemplary. 


\section{Acknowledgements}

I would like to thank Matt Ryan, Carolyn Hendriks, Rikki Dean, Claire Mellier-Wilson and Tim Hughes for helpful feedback on earlier drafts of the paper. I also thank the JDD editors and the two anonymous reviewers for helping refine the paper for publication. Finally, I especially thank the organisers and participants at the Kingston-uponThames Citizens' Assembly on Air Quality for an amazing and enriching experience.

\section{Competing Interests}

The author has no competing interests to declare.

\section{References}

Achen, C. H., \& Bartels, L. M. (2017). Democracy for realists: Why elections do not produce responsive government (Vol. 4). Princeton University Press. DOI: https://doi.org/10.1515/9781400888740

Black, L. W. (2009). Listening to the city: Difference, identity, and storytelling in online deliberative groups. Journal of Public Deliberation, 5(1), 4. DOI: https://doi.org/10.16997/jdd.76

Boswell, J., \& Corbett, J. (2015). Stoic democrats? Antipolitics, elite cynicism and the policy process. Journal of European Public Policy, 22(10), 1388-1405. DOI: https://doi.org/10.1080/13501763.2015.1010561

Boswell, J., Corbett, J., \& Rhodes, R. A. W. (2019). The art and craft of comparison. Cambridge University Press. DOI: https://doi. org/10.1017/9781108561563

Carson, L. (2017a). Importance of Facilitation. new Democracy Research and Development Note.

Carson, L. (2017b). Enhancing citizen jurors' critical thinking capacity. newDemocracy Research and Development Note.

Christensen, H. S., Himmelroos, S., \& Grönlund, K. (2017). Does deliberation breed an appetite for discursive participation? Assessing the impact of first-hand experience. Political Studies, 65(1_suppl), 64-83. DOI: https://doi. org/10.1177/0032321715617771

Curato, N., Dryzek, J. S., Ercan, S. A., Hendriks, C. M., \& Niemeyer, S. (2017). Twelve key findings in deliberative democracy research. Daedalus, 146(3), 28-38. DOI: https://doi.org/10.1162/DAED_a_00444

De Volo, L. B., \& Schatz, E. (2004). From the inside out: Ethnographic methods in political research. PS: Political Science \& Politics, 37(2), 267-271. DOI: https://doi.org/10.1017/S1049096504004214

Dean, R., Boswell, J., \& Smith, G. (2020). Designing democratic innovations as deliberative systems: The ambitious case of NHS citizen. Political Studies, 68(3), 689-709. DOI: https://doi. org/10.1177/0032321719866002

Dryzek, J. S. (2000). Deliberative democracy and beyond: Liberals, critics, contestations. Oxford University Press on Demand.

Dryzek, J. S., Bächtiger, A., Chambers, S., Cohen, J., Druckman, J. N., Felicetti, A., ... \& Landemore, H. (2019). The crisis of democracy and the science of deliberation. Science, 363(6432), 1144-1146. DOI: https://doi.org/10.1126/science.aaw2694

Elstub, S., \& Escobar, O. (2019). A Typology of Democratic Innovations. In S. Elstub \& O. Escobar (Eds.), Handbook of Democratic Innovation and Governance. Edward Elgar Publishing. DOI: https:// doi.org/10.4337/9781786433862

Ercan, S. A., Hendriks, C. M., \& Boswell, J. (2017). Studying public deliberation after the systemic turn: The crucial role for interpretive research. Policy \& Politics, 45(2), 195-212. DOI: https://doi.org/10.1332 /030557315X14502713105886

Escobar, O. (2015). Scripting deliberative policy-making: Dramaturgic policy analysis and engagement knowhow. Journal of Comparative Policy Analysis: Research and Practice, 17(3), 269-285. DOI: https://doi.org/10. 1080/13876988.2014.946663

Fishkin, J. S. (2009). When the people speak: Deliberative democracy and public consultation. Oxford University Press.

Forester, J. (1999). The deliberative practitioner: Encouraging participatory planning processes. Mit Press.

Fung, A., \& Wright, E. O. (2003). Deepening democracy: Institutional innovations in empowered participatory governance. London: Verseo.

Goodin, R. E. (2008). Innovating democracy: Democratic theory and practice after the deliberative turn. OUP Oxford. DOI: https://doi.org/10.1093/acprof: oso/9780199547944.001.0001

Grönlund, K., Setälä, M., \& Herne, K. (2010). Deliberation and civic virtue: lessons from a citizen deliberation experiment. European Political Science Review, 2(1), 95-117. DOI: https://doi.org/10.1017/ S1755773909990245

Hajer, M. A. (2005). Setting the stage: A dramaturgy of policy deliberation. Administration \& society, 36(6), 624-647. DOI: https://doi. org/10.1177/0095399704270586

Hartz-Karp, J., Anderson, P., Gasti, J., \& Felicetti, A. (2010). The Australian Citizens' Parliament: Forging shared identity through public deliberation. Journal of public affairs, 10(4), 353-371. DOI: https://doi. org/10.1002/pa.370

Hendriks, C. M. (2012). The politics of public deliberation: Citizen engagement and interest advocacy. Springer. DOI: https://doi.org/10.1057/9780230347564_1

Hendriks, C. M., Ercan, S. A., \& Boswell, J. (2020). Mending Democracy: Democratic Repair in Disconnected Times. Oxford University Press, USA. DOI: https://doi.org/10.1093/ oso/9780198843054.001.0001

Hibbing, J. R., \& Theiss-Morse, E. (2002). Stealth democracy: Americans' beliefs about how government should work. Cambridge University Press. DOI: https:// doi.org/10.1017/CBO9780511613722

Jacquet, V. (2017). Explaining non-participation in deliberative mini-publics. European Journal of Political Research, 56(3), 640-659. DOI: https://doi. org/10.1111/1475-6765.12195 
Johnson, G. F. (2015). Democratic illusion: deliberative democracy in Canadian public policy (Vol. 49). University of Toronto Press.

Karpowitz, C. F., \& Mansbridge, J. (2005). Disagreement and consensus: The need for dynamic updating in public deliberation. Journal of Public Deliberation, 1(1), 2. DOI: https://doi.org/10.16997/jdd.25

Knobloch, K. R., \& Gastil, J. (2015). Civic (re) socialisation: The educative effects of deliberative participation. Politics, 35(2), 183-200. DOI: https:// doi.org/10.1111/1467-9256.12069

Knobloch, K. R., Gastil, J., Feller, T., \& Richards, R. C. (2014). Empowering citizen deliberation in direct democratic elections: A field study of the 2012 Oregon Citizens' Initiative Review. Field Actions Science Reports. The journal of field actions, (Special Issue 11).

Lee, C. W. (2014). Do-it-yourself democracy: The rise of the public engagement industry. Oxford University Press. DOI: https://doi.org/10.1093/acprof: oso/9780199987269.001.0001

Niemeyer, S., \& Dryzek, J. S. (2007). The ends of deliberation: meta-consensus and inter-subjective rationality as ideal outcomes. Swiss political science review, 13(4), 497-526. DOI: https://doi. org/10.1002/j.1662-6370.2007.tb00087.x

Parkinson, J. (2004). Why deliberate? The encounter between deliberation and new public managers. Public administration, 82(2), 377-395. DOI: https://doi. org/10.1111/j.0033-3298.2004.00399.x

Pedrini, S. (2014). Deliberative capacity in the political and civic sphere. Swiss Political Science Review, 20(2), 263-286. DOI: https://doi.org/10.1111/spsr.12074

Prosser, B., Renwick, A., Giovannini, A., Sandford, M., Flinders, M., Jennings, W., ... \& Ghose, K. (2017).
Citizen participation and changing governance: cases of devolution in England. Policy \& Politics, 45(2), 251-269. DOI: https://doi.org/10.1332/0305573 17X14895974141213

Renn, O., Webler, T., Rakel, H., Dienel, P., \& Johnson, B. (1993). "Public participation in decision making: A three step procedure" Policy Sciences, 26, 191-214. DOI: https://doi.org/10.1007/BF00999 716

Ryfe, D. M. (2006). Narrative and deliberation in small group forums. Journal of Applied Communication Research, 34(1), 72-93. DOI: https://doi. org/10.1080/00909880500420226

Sanders, L. M. (1997). Against deliberation. Political theory, 25(3), 347-376. DOI: https://doi. org/10.1177/0090591797025003002

Settle, C. (2016). Democratising health policy with deliberative mini-publics: Responsibilities, pathologies, and paradoxes. PhD Thesis, ANU.

Smith, G. (2009). Democratic innovations: Designing institutions for citizen participation. Cambridge University Press. DOI: https://doi.org/10.1017/ CBO9780511609848

Soss, J. (2018). On Casing a Study versus Studying a Case. Qualitative and Multi-Method Research, 16(1), 21-27.

Spada, P., \& Ryan, M. (2017). The failure to examine failures in democratic innovation. PS: Political Science \& Politics, 50(3), 772-778. DOI: https://doi. org/10.1017/S1049096517000579

Tyers, R., Huckins, J., \& Boswell, J. (2020). Assessing the \#Delibwave in the UK: A report on the impact of Citizens' Assemblies on British government. Policy Report: Public Policy at Southampton.

How to cite this article: Boswell, J. (2021). Seeing Like a Citizen: How Being a Participant in a Citizens Assembly Changed Everything I thought I Knew about Deliberative Mini-Publics. Journal of Deliberative Democracy, 17(2), pp. 1-12. DOl: https://doi. org/10.16997/jdd.975

Submitted: 11 June $2020 \quad$ Accepted: 09 November $2020 \quad$ Published: 22 November 2021

Copyright: (c) 2021 The Author(s). This is an open-access article distributed under the terms of the Creative Commons Attribution 4.0 International License (CC-BY 4.0), which permits unrestricted use, distribution, and reproduction in any medium, provided the original author and source are credited. See http://creativecommons.org/licenses/by/4.0/ 